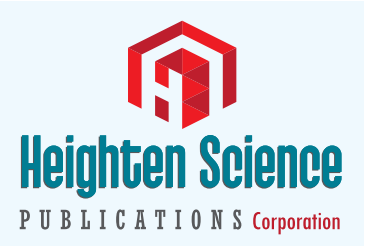

ISSN

2639-6777
Research Article

\section{Phylogenetic analysis of} metalloprotease from transcriptome of venom gland of Hemiscorpius lepturus

\author{
Fatemeh Kazemi-Lomedasht*, Delavar Shahbazzadeh and \\ Mahdi Behdani \\ Venom \& Biotherapeutics Molecules Laboratory, Biotechnology Research Center, Pasteur \\ Institute of Iran, Tehran, Iran
}

*Address for Correspondence: Fatemeh Kazemi-Lomedasht, Assistant Professor, Ph.D of Medical Biotechnology, Tehran, Iran, Tel: +98 021-66112529; Email: fa_kazemi@pasteur.ac.ir

Submitted: 05 December 2018

Approved: 04 February 2019

Published: 05 February 2019

Copyright: @ 2019 Kazemi-Lomedasht F, et al. This is an open access article distributed under the Creative Commons Attribution License, which permits unrestricted use, distribution, and reproduction in any medium, provided the original work is properly cited

Keywords: Hemiscorpius lepturus; Venom component; Phylogeny; Metalloproteinases; Iranian scorpion

Check for updates

\section{Abstract}

Hemiscorpius lepturus is a dangerous scorpion and referred to health concern issue in Khuzestan, Iran. The venom of H.lepturus is cytotoxic and its effect is similar to spider Loxosceles reclusa. Metalloproteinases are the important class of enzymes in the venom that has hemorrhagic activity. The early finding suggests the existence of metalloproteases in the transcriptome of venom gland of H.lepturus. Phylogenetic analysis was accomplished to reveal the evolutionary relationship of identified metalloproteases. The phylogenetic tree was constructed by Molecular Evolutionary Genetics Analysis software and neighbor-joining method. Results showed among three sequences, two metalloproteinases named HLMP1 and HLMP3 of H.lepturus were most close to spider P. tepidariorum. The third sequence named HLMP2 was different and formed an independent clade in the phylogenetic tree. The results suggest that the sequence of metalloproteases in the venom component of H.lepturus is similar to the spider than the scorpion.

\section{Introduction}

Hemiscorpius lepturus is one of the dangerous scorpions of Iran. The pathological effects of H.lepturus are different of other scorpions and results in failure of kidney, liver as well as blood cells [1]. Various studies have evaluated the venom component of H.lepturus and various toxic peptides and proteins of H.lepturus have been identified like: hemitoxin [2], hemicalcin [3], heminecrolysin [4] and hemilipin [5]. Transcriptome analysis of venom gland of H.lepturus was performed in previous study and whole venom component of this scorpion was identified [6]. Early finding of transcriptome analysis suggest existence of metalloprotease enzyme in the venom gland of H.lepturus $[6,7]$. However the metalloprotease activity of H.lepturus has been evaluated using zymography analysis [8]. Matrix metalloproteinases (MMPs) play a role in growth and cell differentiation through direct and indirect mechanism on growth factors function [9-11]. It seems that MMP can affect cellular attachment to the matrix by proteolysis of the adhesion sites [12]. In the early stage, MMP plays a role in cell proliferation and cell survival of tumor cells [13]. There is diversity in function of various metalloproteinases of different organisms [14]. Metalloproteases are important enzymes in the venom component. They play important role in hemorrhagic activity of venom [15]. A metalloproteinase named, BumaMPs1, has been identified in the venom of Buthus martensi scorpion) [15]. BumaMPs1 characterized as independent metalloproteinase of others [15]. Phylogenetic analysis results showed that BumaMP1 is most similar to Mesobuthus eupeus scorpion metalloproteinase [15]. Here, phylogenetic analysis of the metalloproteinase (identified in transcriptome of venom glnad) of H.lepturus was performed for the first time to identify evolutionary relationship of the enzyme in three different taxa: Insecta, Ophidia and Arachnida. 


\section{Materials and Methods}

\section{Metalloproteinase sequences}

The transcriptome analysis of venom gland of Hemiscorpius lepturus was accomplished in previous work [6]. Metalloproteinase sequences identified in the transcriptome and submitted to NCBI as follows accession numbers: HLMP1; KX924496, HLMP2; KX924497, HLMP3; KX924498 [6,7]. The protein sequences were aligned using Basic Local Alignment Search Tool (BLAST) of National Center for Biotechnology Information (NCBI). The BLASTp tool was used and alignment was performed in Nonredundant protein sequences (nr databank) (http://nlm.nih.gov/BLAST/).

\section{Phylogenetic analysis}

To construct phylogenetic tree, the sequences with high similarity to the metaloprotease sequences of H.lepturus were selected from three taxa: Arachnida (Latrodectus Hesperus ADV40108; Tityus serrulatus CDJ26716.1; Stegodyphus mimosarum KFM63177.1; Parasteatoda tepidariorum XP_015909675.1, XP_015919212.1, XP_021003544.1; Tityus serrulatus CDJ26717.1; Ixodes scapularis XP_002406806.1, XP_002435824.1), Ophidia (Thamnophis sirtalis XP_013907739.1; Protobothrops mucrosquamatus XP_015680512.1; Python bivittatus XP_007429967.1) and Insecta (Pogonomyrmex barbatus XP_011632701.1; Pediculus humanus corporis XP_002426660.1; Zootermopsis nevadensis XP_021917577.1; Stomoxys calcitrans XP_013099168.1; Wasmannia auropunctata XP_011692954.1, XP_011704691.1; Halyomorpha halys XP_014273620.1; Aedes albopictus XP_019532310.1; Camponotus floridanus XP_011253904.1; Helicoverpa armigera XP_021196322.1; Rhagoletis zephyria XP_017463716.1). The polygenetic tree was constructed by Molecular Evolutionary Genetics Analysis software (MEGA 5) using neighbor-joining method and 1000 bootstrap replicate [16,17].

\section{Results}

\section{Alignment analysis}

Alignment of HLMP1 in nr databank of NCBI showed 50, 51, 53 and 56 percent identity with astacin-like metalloprotease, [Latrodectus hesperus ADV40108.1], astacinlike metallopeptidase 1 protein [Tityus serrulatus CDJ26716.1], Zinc metalloproteinase nas-4, partial [Stegodyphus mimosarum KFM63177.1], astacin-like metalloprotease toxin5 [Parasteatoda tepidariorum XP_015909675.1, XP_015909677.1], respectively. Alignment results of HLMP2 showed 35, 36 and 45 percent identity to metalloprotease 1 [Ixodes persulcatus AIE44747.1], metalloprotease [Ixodes scapularis XP_002435641.1], metalloserrulase 19 [Tityus serrulatus AM002561.1], respectively. Alignment analysis of HLMP3 showed 50, 51, 53 and 56 percent identity to astacin-like metalloprotease [Latrodectus hesperus ADV40108.1], astacin-like metallopeptidase 1 protein [Tityus serrulatus CDJ26716.1], Zinc metalloproteinase nas-4 [Stegodyphus mimosarum KFM63177.1], astacin-like metalloprotease toxin 5 [Parasteatoda tepidariorum XP_015909675.1, XP_015909677.1], respectively.

\section{Phylogenetic analysis}

Phylogenetic tree was constructed using 23 sequences of three different taxa: Insecta ( 11 sequences), Ophidia ( 3 sequences) and Arachnida ( 9 sequences).There were different species in Arachnida taxa: scorpions (2 sequences), spiders (5 sequences) and tick ( 2 sequences). As it can be seen in figure 1 HLMP1 and HLMP3 organized a single calde close to Parasteatoda tepidariorum (XP_021003544.1) and HLMP2 was in other clade. The results indicate that metalloprotease sequences of H.lepturus scorpion are similar to P.tepidariorum spider.

\section{Discussion}

Metalloproteinases exist in the venom of different venomous animal like snake and scorpion $[8,15,18]$. Hemorrhagic activity of venom is related to the presence 


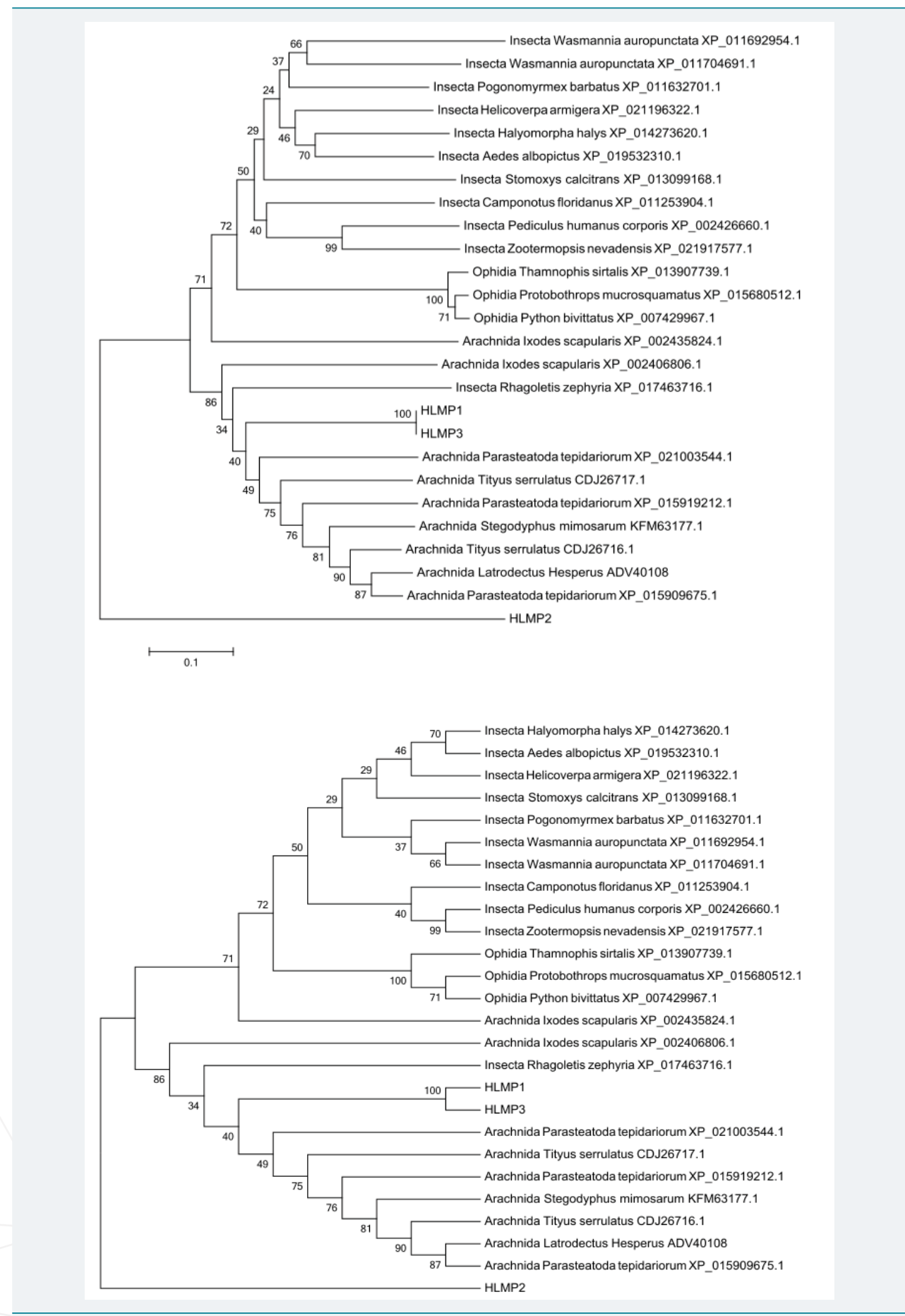

Figure 1: Phylogenetic tree.The phylogenetic tree was constructed by MEGA 5 using neighbor-joining method and 1000 bootstrap replicate. A: Orginal tree, B: Bootstrap consensus tree. HLMP1 and HLMP3 organized a single calde) close to Parasteatoda tepidariorum (XP_021003544.1)). HLMP2 formed an independent clade.

of enzymes like metalloproteinase in the venom [15]. The metalloproteinases fall into different groups depending on their metal atom [19]. Three sequences in the transcriptome of H.lepturus are identified that showed similarity to metalloproteinase sequences. HLMP1 and HLMP3 showed similarity with Astacin-like metalloprotease toxin but HLMP2 showed similarity with venom metalloproteinase antarease. Antarease-like Zinc-metalloproteases in the venom of scorpion Tityus serrulatus leads to acute panceratitis [20]. Targeting of metalloprotease in the scorpion venom is novel anti-venom strategy [20]. In phylogenetic analysis of three metalloproteinases from transcriptome of venom gland of H.Irpturus, two clade was organized. The HLMP1 and HLMP3 were in one clade and HLMP2 was in independent clade. The results 
indicating difference of theses sequences with each other. The analysis was performed on the sequences that achieved by transcriptome analysis of venom gland. It has been reported that some sequences in the transcriptome may not detect in the proteome and some sequences in the proteome may not predict in the transcriptome [21]. Therefore, it seems necessary to compare transcriptome and proteome of H.lepturus venom at same time to analyze the accuracy of achieved sequences.

\section{Conclusion}

Here, for the first time phylogenetic analysis of three metalloproteinase sequences from transcriptome of venom gland of H.lepturus was performed. Results showed that two metalloproteinases (HLMP1 and HLMP3) of H.lepturus are most close to spider P.tepidariorum. However, the sequence of HLMP2 was differ from HLMP1 and HLMP3 and formed an independent clade in phylogenetic tree. However further studies on proteome of H.lepturus is needed.

\section{Acknowledgment}

This study was supported by Pasteur Institute of Iran, Tehran, Iran. The authors warmly thanks from Pasteur Institute of Iran, Tehran, Iran for supporting current study.

\section{References}

1. Jalali A, Pipelzadeh MH, Sayedian R, Rowan E. A review of epidemiological, clinical and in vitro physiological studies of envenomation by the scorpion Hemiscorpius lepturus (Hemiscorpiidae) in Iran. Toxicon. 2010; 55, 173-179. Ref.: https://goo.gl/zCWt8B

2. Srairi-Abid N, Shahbazzadeh D, Chatti I, Mlayah-Bellalouna S, Mejdoub H, et al. Hemitoxin, the first potassium channel toxin from the venom of the Iranian scorpion Hemiscorpius lepturus. FEBS $\mathrm{J}$. 2008; 275, 4641-4650. Ref.: https://goo.gl/q6K6iW

3. Shahbazzadeh D, Srairi-Abid N, Feng W, Ram N, Borchani L, et al. Hemicalcin, a new toxin from the Iranian scorpion Hemiscorpius lepturus which is active on ryanodine-sensitive $\mathrm{Ca} 2+$ channels. Biochem J. 2007; 404, 89-96. Ref.: https://goo.gl/EUWiJD

4. Borchani L, Sassi A, Shahbazzadeh D, Strub JM, Tounsi-Guetteti $H$, et al. Heminecrolysin, the first hemolytic dermonecrotic toxin purified from scorpion venom. Toxicon. 2011; 58: 130-139. Ref.: https://goo.gl/CF2HhS

5. Jridi I, Catacchio I, Majdoub H, Shahbazeddah D, El Ayeb M, et al. Hemilipin, a novel Hemiscorpius lepturus venom heterodimeric phospholipase $A 2$, which inhibits angiogenesis in vitro and in vivo. Toxicon. 2015; 105: 34-44. Ref.: https://goo.gl/pavzMB

6. Kazemi-Lomedasht F, Khalaj V, Bagheri KP, Behdani M, Shahbazzadeh D. The first report on transcriptome analysis of the venom gland of Iranian scorpion, Hemiscorpius lepturus. Toxicon. 2017; 125: 123-130. Ref.: https://goo.gl/oKcbqM

7. Jahdasani R, Jamnani FR, Behdani M, Habibi-Anbouhi M, Yardehnavi N, et al. Identification of the immunogenic epitopes of the whole venom component of the Hemiscorpius lepturus scorpion using the phage display peptide library. Toxicon. 2016; 124: 83-93. Ref.: https://goo.gl/dmCPUU

8. Seyedian R, Pipelzadeh MH, Jalali A, Kim E, Lee H, et al. Enzymatic analysis of Hemiscorpius lepturus scorpion venom using zymography and venom-specific antivenin. Toxicon. 2010; 56: 521-525. Ref.: https://goo.gl/NEV5Wi

9. Imai K, Hiramatsu A, Fukushima D, Pierschbacher MD, Okada Y. Degradation of decorin by matrix metalloproteinases: identification of the cleavage sites, kinetic analyses and transforming growth factor- $\beta 1$ release. Biochem J. 1997; 322: 809-814. Ref.: https://goo.gl/5JXeHh

10. Buckley A. Potential Therapeutic Efficacy of a Novel Metalloproteinase Inhibitor, Extracellular Matrix Protection Factor 1, in Human Osteoarthritic Chondrocyte Primary Cultures. 2016; Ref.: https://goo.gl/Nf3KaR

11. Kim BJ, Hur JW, Park JS, Kim JH, Kwon TH, et al. Expression of matrix metalloproteinase- 2 and- 9 in human ligamentum flavum cells treated with tumor necrosis factor- $\alpha$ and interleukin-1 $\beta$. Journal of Neurosurgery: Spine. 2016; 24: 428-435. Ref.: https://goo.gl/ujEXVE

12. Giannelli G, Falk-Marzillier J, Schiraldi O, Stetler-Stevenson WG, Quaranta V, et al. Induction of cell migration by matrix metalloprotease-2 cleavage of laminin-5. Science. 1997; 277: 225-228. Ref.: https://goo.gl/5gtZRb 
13. Rudolph-Owen LA, Chan R, Muller WJ, Matrisian LM. The matrix metalloproteinase matrilysin influences early-stage mammary tumorigenesis. Cancer Res. 1998; 58: 5500-5506. Ref.: https://goo.gl/emSDLZ

14. Azofeifa-Cordero G, Arce-Estrada V, Flores-Díaz M, Alape-Girón A. Immunization with cDNA of a novel P-III type metalloproteinase from the rattlesnake Crotalus durissus durissus elicits antibodies which neutralize $69 \%$ of the hemorrhage induced by the whole venom. Toxicon. 2008; 52: 302-308. Ref.: https://goo.gl/yp6QcM

15. Xia X, Ma Y, Xue S, Wang A, Tao J, et al. Cloning and molecular characterization of BumaMPs1, a novel metalloproteinases from the venom of scorpion Buthus martensi Karsch. Toxicon. 2013; 76: 234-238. Ref.: https://goo.gl/y2XLYP

16. Zuckerkandl E, Pauling L. Evolutionary divergence and convergence in proteins. Evolving genes and proteins. 1965; 97: 97-166. Ref.: https://goo.gl/FVAFwU

17. Tamura K, Peterson D, Peterson N, Stecher G, Nei M, et al. MEGA5: molecular evolutionary genetics analysis using maximum likelihood, evolutionary distance, and maximum parsimony methods. Mol Biol Evol. 2011; 28: 2731-2739. Ref.: https://goo.gl/vSwynC

18. Fox JW, Serrano SM. Insights into and speculations about snake venom metalloproteinase (SVMP) synthesis, folding and disulfide bond formation and their contribution to venom complexity. FEBS $J$. 2008; 275: 3016-3030. Ref.: https://goo.gl/XT6VNb

19. Hooper NM. Families of zinc metalloproteases. FEBS lett. 1994; 354: 1-6. Ref.: https://goo.gl/Tc3weV

20. Ortiz E, Rendón-Anaya M, Rego SC, Schwartz EF, Possani LD. Antarease-like Zn-metalloproteases are ubiquitous in the venom of different scorpion genera. Biochim Biophys Acta. 1840: 2014; 1738-1746. Ref.: https://goo.gl/jXeZxs

21. Shan LL, Gao JF, Zhang YX, Shen SS, He Y, et al. Proteomic characterization and comparison of venoms from two elapid snakes (Bungarus multicinctus and Naja atra) from China. J Proteomics. 2016; 138: 83-94. Ref.: https://goo.gl/4qoBDW 